\title{
17 \\ La ética empresarial como ética aplicada: Una propuesta de ética empresarial dialógica
}

\author{
DOMINGO GARCÍA-MARZÁ \\ Universidad Jaume I de Castellón
}

\section{INTRODUCCIÓN}

LAS ÉTICAS APLICADAS CONSTITUYEN EN LA ACTUALIDAD uno de los ámbitos más importantes dentro de la estructuración de la sociedad civil. Sin embargo, dentro de la reflexión ética es difícil encontrar posiciones claras acerca de su estatuto y de su metodología. Acabar con este desfase entre su actual significación práctica y la falta de una teoría que de razón de sus principios y orientaciones es, a mi juicio, uno de los retos pendientes de la filosofía moral que más urge afrontar. El presente artículo intenta presentar esquemáticamente algunas notas acerca de cómo una ética empresarial dialógica puede responder a esta cuestión que remite, en definitiva, a la ya clásica relación entre teoría y praxis.

En el caso de la ética económica y empresarial esta aclaración conceptual es, si cabe, más necesaria que nunca ante una situación que supone, sin lugar a dudas, un nuevo escenario para la empresa y para su perspectiva ética. En primer lugar, la pérdida del protagonismo del estado ha conducido a la resignación actual con la que vemos como el mercado se ocupa no sólo de definir la eficacia, sino también el bien común y la justicia. En segundo lugar, el actual proceso de globalización enfatiza aún más el hecho social básico del pluralismo, esto es, nos fuerza en la

Retos pendientes en ética y polfíca, ed, José Rubio. Carracedo. José $\mathrm{M}^{*}$ Rosales y Manuel Toscano Suplemento $5(2000)$ de Conirustes. Revisha Interdisciplinter de Filinofía. [ISSN: 1136-9922], pp. 235-246 
búsqueda de criterios universales de lo que signifique o pueda significar bueno o malo en cualquier contexto económico y empresarial.

Frente a esta situación, una reflexión ética sobre la empresa no puede dejar de afrontar el reto de justificar un enfoque crítico que permita conceptualizar de nuevo la cuestión básica del papel de la empresa en nuestra sociedad y, al mismo tiempo, un enfoque universalista, capaz de responder a los problemas de validez moral en contextos económicos globalizados.

La intención de esta comunicación es apuntar algunas ideas en esta dirección. El objetivo es presentar los principios de una ética empresarial dialógica, esto es, un enfoque ético que intenta aplicar al ámbito empresarial la racionalidad procedimental que define a la ética discursiva, tal como K. O. Apel y J. Habermas la presentan'1. Para ello, en primer lugar, entraremos en el terreno de las éticas aplicadas con el fin de evitar dos errores comunes y, a continuación, expondremos algunos rasgos de esta propuesta de ética empresarial.

\section{DE LA ÉTICA A LA ÉTICA APLICADA}

No podemos detenernos en la especificidad del ámbito moral2 2 . Sólo recordar que con esta expresión nos referimos normalmente a la capacidad humana de deliberar y decidir y, con ello, de responder de lo que hacemos o dejamos de hacer, de lo que decimos o callamos. Este continuo «justificarse» 0 «ajustarse» a la realidad define la actuación de las personas y la constitución de sus organizaciones ${ }^{3}$. Ambos niveles responden al hecho antropológico básico de la libertad y de ambos niveles debe ocuparse una teoría ética que quiera dar razón del ámbito moral.

Para algunos autores la teoría ética debe ocuparse de fundamentar un punto de vista moral y poco más. Por punto de vista moral entienden la fundamentación o justificación de un criterio, procedimiento o principio desde donde decidir la validez moral de nuestras acciones, normas e instituciones. Como todos ya sabemos, la ética discursiva lleva a cabo un programa de fundamentación pragmático-trascendental, que le permite llegar con éxito, esa es mi opinión, a definir de la siguiente forma el

1 Este trabajo se inserta en el Proyecto de Investigación interuniversitario PB971419-C02-02 financiado por el Ministerio de Educación y Ciencia titulado «La ética discursiva como núcleo de las éticas aplicadas» y desarrollado por la Universitat Jaume I de Castellón y la Universidad de Valencia

2 Cf. A. Cortina, Etica sin moral. Madrid:Tecnos, 1990.

3 Cf. J. L. L. Aranguren, Etica. Madrid: Alianza, 1979. 
principio moral: «una acción, norma o institución es justa si es aceptada por todos los afectados en un discurso práctico bajo condiciones perfectas de simetría e igualdad en las oportunidades de participación» 4 .

No obstante, la aportación de la ética, la reflexión de los éticos no puede quedarse ahí. La relación con la moralidad quedaría incompleta si no atendiéramos a una cuestión fundamental: la aplicación a la praxis, tanto individual como institucional, del principio moral reconstruido. Mientras que la teoría ética se encarga de explicitar y fundamentar el punto de vista moral, esta sería la tarea básica de la ética aplicada que, presuponiendo la validez del criterio moral, se enfrenta a la cuestión de su realización. La diferencia radica en que el tema no es ahora explicar en qué consiste la obligatoriedad moral, sino interpretar esta obligatoriedad en un ámbito específico y determinado, desde el punto de vista histórico-social5.

En este sentido pragmático o práctico de la ética lo que se intenta es perder el miedo a lo concreto y avanzar orientaciones posibles de la acción en vistas de la realización del principio moral propuesto. Estamos ante una ética «especial» encargada de interpretar la incondicionalidad de la moralidad con relación a determinados ámbitos de vida y acción. La idea rectora que define la importancia de la ética aplicada es que con ella ya se pide, de forma directa, «entrar a formar parte activa en la responsabilidad por el curso de los acontecimientos» 6 .

En definitiva, seguimos en el terreno de la razón práctica pero su voz no es ya el principio de universalización, que nos permite definir la validez de una norma si esta expresa intereses generales, sino el principio de adecuación, que nos permite la aplicación imparcial de la norma válida «prima facie» a un contexto particular, teniendo en cuenta todos los aspectos relevantes. Para la adecuación correcta del criterio moral a la praxis son necesarios criterios de coherencia, de compatibilidad, entre la validez fundamentada y las circunstancias de la problemática concreta $^{7}$. De ahí que, como después propondremos, la adecuación sea un paso intermedio entre la idea y su realización práctica. Las situaciones de aplicación de normas morales son interpretadas siempre desde el horizonte de una determinada Lebenswelt, se refieren a relaciones sociales establecidas, a contextos culturales, a intereses ya definidos y a motiva-

4 Cf. Al respecto J. Habermas, Facticidad y validez. Madrid: Trotta, 1998, p. 75 , y D. García-Marzá, Ética de la justicia. Madrid: 1992, p.78.

5 O. Hoffe, Estrategias de lo humano. Buenos Aires: Alfa, 1979, p. 102.

6 K. Bayertz, Praktische Philosophie. Hamburg: Rowoholts, 1991, p. 20.

7 K. Gunter, Der Sinn der Angemessenheit. Frankfurt: Suhrkamp, 1988, p. 53. 
ciones particulares de las personas. El tema no es ahora la validez de la norma para todos los afectados, sino sus consecuencias con relación a estas características. Siempre con la necesidad, como ética aplicada, de contar con el sentido propio de cada praxis o institución, con su propia lógica, sin intentar establecer «deductivamente» la consideración moral de la acción8.

Esta es la razón por la que la perspectiva normativa que caracteriza a la filosofía refuerce su proceder dialógico cuando entra en el terreno de la ética aplicada 9 . Los hechos nunca son «neutros», se encuentran ya siempre interpretados desde una perspectiva teórica que reconoce los datos y descubre los problemas. De ahí que se requiera un trabajo interdisciplinar conjunto, una cooperación con otras disciplinas para poder realizar, por ejemplo, un cálculo de consecuencias, para identificar intereses, para formular posibilidades alternativas de acción, etc.

En el caso de la ética discursiva, en ningún momento puede ser interpretado su criterio moral como por ejemplo hace Pieper: «actúa como si fueras miembro de una comunidad ideal de comunicación»10. El procedimiento moral no nos exige, como también malinterpreta Elster, «que habría que aproximarse a la sociedad buena como si ya se estuviera en ella» "I. Apel ha conseguido centrar la cuestión y ha propuesto discutir el problema de la aplicación, denominado por él parte B de la ética, como el «problema moral de la exigibilidad de la aplicación de una ética postconvencional». Esto es, desde el problema de la relatividad de esta exigibilidad con referencia a la eticidad sustancial. No se trata sencillamente de cómo aplicar un principio moral. Se trata de cómo aplicar un principio moral a situaciones donde precisamente no se dan las condiciones apropiadas para tal aplicación. Se trata de unir convicción y responsabilidad dentro de la reflexión ética, de modo que: «la norma básica de la ética de la comunicación debe servir como principio regulativo de mediación y esto significa como una estrategia moral»12. Este par de conceptos encierran la clave interpretativa de la ética aplicada.

Si entramos ya en el terreno de la ética empresarial podremos visualizar más fácilmente dos modalidades bastante frecuentes de apli-

8 Cf. al respecto J. Habermas, Erläuterungen zur Diskursethik. Frankfurt: Suhrkamp, 1991, p. 140; así como A. Cortina, «La ética aplicada como hermenéutica crítica", Isegoría. pp. $327 \mathrm{ss}$

9 Cf. J. Habermas, Wahrheit und Rechfertigung. Frankfurt: Suhrkamp, 1999,

10 A. M. Pieper, Etica y moral. Barcelona: Crítica, 1990, p. 227.

11 J. Elster, Uvas amargas. Barcelona: Península, 1988, p. 58.

12 K. O. Apel, Diskurs und Verantwortung. Frankfurt: Suhrkamp, 1988, p. 273. 
cación que sólo pueden conducir a la autodisolución de la reflexión ética. Debemos evitar tanto un enfoque correctivo (la ética como «libro de recetas») que nos dice cuáles son los límites éticos (externos) de la actividad económica, como un enfoque funcional (la ética «lava más blanco») que sólo considera la ética como un instrumento más para el logro del beneficio económico ${ }^{13}$. El primero se estrella ante el pluralismo de nuestras sociedades y no tiene más remedio que refugiarse en la privacidad de nuestra conciencia o en el convencionalismo de nuestras creencias. El segundo se diluye en la lógica de la eficacia y es incapaz de explicar la validez moral de nuestras acciones e instituciones, de la que, no olvidemos, depende gran parte de su credibilidad o legitimidad.

Ambas posibilidades de aplicación parten de un error básico: la separación entre economía y ética, como si fueran dos mundos diferentes, como si la racionalidad económica pudiera ser, y lo fuera, autosuficiente. Sin entrar en la discusión del positivismo en sus múltiples formas, sí que podemos indagar las oportunidades que aparecen cuando se explicita la relación que de hecho existe entre los dos mundos. Ello implica que una ética aplicada al terreno económico debe afrontar la tarea de mediar entre el elemento teleológico de la racionalidad económica y el imprescindible elemento deontológico de la razón ético-práctica. Esta es la función básica de un enfoque crítico de la ética económica y empresarial.

\section{LA PERSPECTIVA CRÍTICA: EL PAPEL DE LA ÉTICA ECONÓMICA}

Un enfoque crítico no puede reducirse ni a la mera corrección externa de la racionalidad económica, ni a la simple funcionalidad de la ética. Ninguno de los dos momentos puede «dar razón» de nuestro propio lenguaje moral cuando lo utilizamos en los contextos económico-empresariales. Debemos dirigir más bien nuestra atención hacia las condiciones mismas que subyacen a la actividad económica y empresarial y que constituyen sus pilares básicos de sentido y realización. Estamos ante una metodología de corte kantiano, aunque ahora reinterpretada desde la ética discursiva. Ante una reconstrucción pragmático-lingüística de los fundamentos normativos del sentido de la racionalidad económica y de sus instituciones, como es el caso del mercado o de la empresa ${ }^{14}$.

$13 C f$. P. Ulrich, «Korrektive, funktionale oder grundlagenkritische Wirtschaftsethik», in $I W E$, St. Gallen, 1990, pp. 25 ss.

$14 C f$. P. Ulrich, Transformation der ökonomischen Vernunft. Stuttgart: Haupt, 1987, p. 264 ; así como Integrative Wirtschaftsethik. Haupt: Verlag, 1997. 
El calificativo de crítica tiene que ver, metodológicamente, con esta reconstrucción de la razón humana. La ética discursiva consigue la incondicionalidad que le permite hablar de obligatoriedad moral de la reflexión sobre las condiciones de posibilidad de la argumentación, de la posibilidad del acuerdo racional. La tesis que presenta el enfoque discursivo de la ética económica y empresarial es que tal reflexión crítica también es posible para la racionalidad económica y para el sentido de la empresa como organización.

En esta reconstrucción, lo primero que aparece a la vista es que la neutralidad de valor es una farsa. No existe en el mundo social ningún criterio «neutro» de racionalidad económica, por el simple hecho de que no existe en el mundo social la posibilidad de separar vigencia y validez. Por decirlo de otra forma, el mundo social está construido lingüísticamente, a través de las pretensiones de validez que acompañan a cada una de nuestras acciones, normas e instituciones 15 .

De ahí que una propuesta teórica como la de la ética discursiva dé un paso decisivo al situarse metodológicamente en la perspectiva del participante, es decir, del que forma parte, activa o como afectado, en una praxis determinada. Desde esta perspectiva, la tarea básica consiste en explicitar, sacar a la luz, las condiciones del sentido de la praxis económica y empresarial, remitiendo a los presupuestos que aseguran y mantienen la credibilidad social o legitimidad de las actividades económicas. Condiciones o presupuestos que no definen lo fácticamente existente, sino lo que «debería ser». No nos dirán, por ejemplo, cómo se comporta la empresa, sino como debería comportarse para que no pierda el sentido que tiene para todos los participantes, esto es, para todos sus grupos de intereses 16 .

Desde esta posición, y apoyándose en el contenido normativo de nuestra capacidad de comunicación, de establecer diálogos y alcanzar acuerdos, la ética discursiva consigue, a mi juicio, defender un universalismo ético que no rompe con las condiciones marco de nuestras sociedades plurales y democráticas, ya que se limita a las reglas básicas que rigen la resolución discursiva de conflictos. Estamos ante una ética procedimental que define la validez moral de la siguiente forma: «validez moral significa que las normas morales puedan encontrar la aprobación de todos los interesados en la medida en que estos examinan con-

15 Cf. J. Habermas, Facticidad y validez, p. 541; D. García-Marzá, Ética de la justicia, p. 48.

${ }_{16}$ Cf. al respecto A. Cortina, J. Conill, A. Domingo, D. García-Marzá, Etica de la empresa.Claves para una nueva cultura empresarial. Madrid: Trotta, 1994. 
juntamente en discursos prácticos si la correspondiente práctica responde por igual a los intereses de todos» 17 .

Aplicado al terreno de la economía y entendida ésta como «uso racional de los recursos escasos», una ética económica crítica no puede cerrar dogmáticamente la discusión y excluir a los posibles afectados de una discusión posible sobre lo que significa «racional». Términos como beneficio, rendimiento, responsabilidad, necesidad, interés, eficacia, etc., están construidos socialmente y deben, por lo tanto, someterse a una discusión racional acerca de cómo queremos vivir como individuos y como colectivo. De ahí que el principio básico de una ética económica sea el siguiente: «Se entiende como económicamente racional toda acción o toda regulación institucional que ciudadanos libres y capaces podrían haber determinado como "productiva" (wertschaffen) en el entendimiento racional político-económico entre todos los afectados»18.

Se alcanza así el segundo significado del calificativo de crítica, pues desde estos presupuestos siempre nos enfrentamos al status quo existente. La idea que deriva de la ética discursiva, y como explicación de la racionalidad práctica también de la economía, es la necesidad de abrir a la participación de todos los afectados los procesos de decisión económica. Principio que saca a la luz la relación intrínseca entre política, como formación discursiva de la opinión y la voluntad común, y economía, como razón técnica o instrumental. Participación que hoy debe plantearse necesariamente a escala global ${ }^{19}$. Como veremos a continuación, tampoco el sentido de la empresa puede ser ajeno al acuerdo o consenso de todos los participantes en ella.

\section{LA PERSPECTIVA UNIVERSALISTA: EL CONTRATO MORAL DE LA EMPRESA}

En el terreno meso de las organizaciones 20 en lo que podemos denominar en sentido estricto ética empresarial, la aplicación de la ética

17 J. Habermas, La inclusión del otro. Barcelona: Paidós, 1999, p. 67.

18 Cf. P. Ulrich, loc. cit., p. 36.

19 Cf. al respecto D. García-Marzá, «Posibilidades y limites de la democracia internacional», Papeles, 53 (1995), pp. 38-49; así como «Weltpolitik und WeltwirtschaftDie Notwendigkeit einer kosmopolitischen Demokratie», en T. Maak y Y. Lunau, Weltwirtschaftsethik. Stuttgart: Haupt, 1998, pp.123-139.

$20 \mathrm{Cf}$. al respecto G. Enderle,«Zum Zusammenhang von Wirtschaftsethik, Unternehmensethik und Führungsethik», en H. Steinmann y A. Löhr, (hrsg.), Unternehmensethik. Stuttgart: Poeschel, 1991, pp. 173-189; asi como J. W. Weiss, Business Ethics. A Managerial, Stakeholder Approach. California: Wadswokrth, 1994, p.11. 
discursiva parte del supuesto básico de que no se puede hablar de la empresa como una institución privada, puesto que la empresa funciona siempre como un trabajo cooperativo y sus actividades afectan siempre a terceros. Por consiguiente, el principio empresarial del beneficio o ganancia no puede presentarse como un objetivo formal y neutro frente a los intereses en juego. El beneficio es la clave de la empresa, pero depende de cómo y para quién, estamos ante un beneficio justo o moral. Sólo el diálogo y la posterior aceptación por parte de todos los grupos de intereses (Stakeholders) implicados en y/o afectados por la empresa pueden definir la justicia o moralidad de una acción o institución empresarial. De ahí que una ética empresarial dialógica funcione con el siguiente principio moral, aplicación del principio de la ética discursiva al ámbito empresarial:

Una empresa es ética cuando las políticas, decisiones y acciones que adopta, así como las consecuencias y efectos de las mismas respecto a los intereses y valoraciones en juego, podrían ser aceptadas por todos los implicados y afectados, presentes y futuros (y preferibles a las consecuencias de las posibles alternativas conocidas) ${ }^{21}$.

Esta aceptación o consenso no puede darse en cualquier circunstancia, sino que requiere que sólo sean las buenas razones, la convicción racional, las que nos conduzcan a él. Esto lleva a Habermas a postular el discurso práctico como un marco de deliberación donde existen condiciones perfectamente iguales y simétricas de participación. Es decir, no cualquier diálogo justificaría el acuerdo, sino que el acuerdo podría considerarse justo cuando se realice en determinadas condiciones. Condiciones que podemos resumir bajo los siguientes cuatro principios interpretados a partir de diferentes textos de Habermas:

\section{Principio de sinceridad.}

Cuando se entra en un discurso, los interesados no quieren dirimir sus conflictos mediante la violencia o el compromiso (estrategia), lo cual implica obligaciones y derechos argumentativos.

\section{Principio de inclusión.}

Han de participar en el diálogo todos los afectados potenciales, presentes y futuros o, en su caso, sus representantes. Nadie que pueda hacer una contribución relevante puede ser excluido de la participación.

21 Cf. D. García-Marzá, «Del balance social al balance ético», en A. Cortina (ed.), La rentabilidad de la ética para la empresa. Madrid: Visor, 1998. 


\section{Principio de reciprocidad.}

Los participantes han de poder dialogar en unas condiciones que aseguren una completa igualdad de oportunidades y una total simetría en las condiciones de participación.

\section{Principio de simetría.}

Todos los intereses han de ser considerados por igual y abiertos a la revisión argumentativa: repartición simétrica de las libertades comunicativas.

Estos principios no intentan describir una situación real, sino que reconstruyen los presupuestos que «de hecho» pensamos que se cumplen cuando, como participantes, estamos implicados o afectados por una decisión o estructura empresarial. El uso del tiempo «podrían» indica que no estamos ante un criterio operativo de decisión, sino ante una idea regulativa cuya operatividad tiene que realizarse siempre después en la práctica. Pero que, aún así, define nuestra posición, esto es, nuestro convencimiento de que tales condiciones se cumplen suficientemente. Desde esta perspectiva, estos principios definen la validez moral, el horizonte último de valoración desde el que deben «construirse» las razones que apoyen o critiquen nuestras decisiones, acciones, normas e instituciones económicas. Constituyen, por así decirlo, las premisas para un contrato moral, sin el que, siguiendo a Kant, no sería posible «juzgar sobre el valor moral o la falta de valor» 22 . Contrato del que depende, en último lugar, la credibilidad social de la empresa.

Su carácter procedimental obliga al mismo tiempo, a que no sea posible la anticipación monológica de los resultados: nos exige la realización de discursos reales y la implementación de condiciones empresariales (estilos de dirección, organigramas participativos, culturas de integración de los recursos humanos, etc.) que los haga posibles. Como criterio moral muestra sólo el horizonte ideal para poder dar los pasos pragmáticos necesarios hacia su realización, aún sabiendo que sólo es posible alcanzar siempre un cumplimiento aproximado. Lo cual nos conduce a una tensión inevitable entre la idea y el acuerdo económico y/o empresarial alcanzado y convierte en necesaria la consideración de los resultados como falibles y abiertos, por principio, a la revisión. Es decir, nunca, y esto es lo más importante, puede identificarse el acuerdo fáctico con la racionalidad ideal. Esta tensión es el nervio central de toda perspectiva crítica. 
Sin embargo, la idealidad del principio introducido parece conducir a una duda muy razonable: ¿vale la pena esta solución abstracta para el problema de la mediación entre la teoría y la praxis, en nuestro caso, entre la perspectiva ética y la empresa?. La respuesta es afirmativa sólo si comprendemos la ética empresarial dialógica como una ética aplicada en la que la respuesta a la praxis, su responsabilidad «por el curso de los acontecimientos», se realiza en tres niveles, en tres pasos, analíticamente diferentes, pero absolutamente interrelacionados:

\section{Nivel de justificación.}

Comprometido con la prueba o fundamentación de la validez moral de la acción que se pretende evaluar o la norma que se quiere aplicar al terreno empresarial. Se requiere la aplicación del principio moral introducido, esto es, el punto de vista moral de lo que es bueno para todos, de los intereses generalizables, de aquello con lo que todos podrían estar de acuerdo.

\section{Nivel de adecuación.}

Encargado de la interpretación de los principios morales desde el ámbito económico y empresarial y, en consecuencia, del ajuste entre la lógica de la universalización y el sentido propio de la actividad empresarial. Definiendo, por ejemplo, qué concepción de la empresa deriva del principio discursivo, qué concepto de beneficio, qué estructura participativa, etc. Nos movemos aún en el terreno normativo, pero se trata aquí de máximas de acción que nos ayuden en la plasmación de los principios morales.

Para ello es necesario «operativizar» el principio de la ética empresarial dialógica y, en mi opinión, la Teoría de los Stakeholder ofrece una óptima complementación de las ideas expuestas. Se trata de buscar estrategias metodológicas que nos permitan integrar las ideas éticas con las realidades concretas. Con esta complentación se consigue, al mismo tiempo, avanzar en una teoría normativa de los stakeholders que no renuncie a su universalismo 23 .

\section{Nivel de resolución.}

El principio de esta ética empresarial discursiva hace hincapié en un aspecto básico: las respuestas concretas deben estar siempre, y necesa-

23 Cf. para la utilización de esta metodología D. García-Marzá (dir.), El conflicto ecológico de la Central Térmica de Andorra (Teruel): un caso de ética empresarial. Castellón: Ed. Univ. Jaume I, 1998. 
riamente, en manos de los propios afectados. A diferencia del enfoque correctivo, aquí ningún ético ni ningún economista o político puede, por sí mismo, decidir la validez moral de una actuación o institución económica. Eso sí, puede avanzar y concretar propuestas para su discusión y aceptación posterior por el círculo de los implicados y/o de sus representantes. De ahí la importancia actual de la ética empresarial entendida como instrumento de gestión. Por ejemplo, de los comités de ética, como verdaderos equipos interdisciplinares que pueden actuar desde las diferentes implicaciones empresariales.

Esta idea del contrato moral, como marco de referencia para todo contrato social o equilibrio de intereses, no es algo «inventado» por la teoría. La teoría ética lo que pretende es «dar razón» de una idea que subyace al sentido de la empresa como institución social. Se trata de mostrar la suma e interrelación de las expectativas sociales e individuales que subyacen a los diferentes mecanismos de coordinación que rigen en la empresa y en sus relaciones con el mercado y la sociedad. Expectativas que no suelen estar explícitas y que, sin embargo, constituyen desde su contenido cognitivo la base racional de toda pretensión de legitimidad.

Tal como la entiende la ética empresarial dialógica la idea del contrato moral se estructura en estos tres pasos que van desde la idea del acuerdo bajo condiciones de simetría hasta la definición y concreción de los grupos de afectados y/o implicados y de sus intereses. Tenemos así un principio moral aplicable en cualquier contexto y situación que, al apoyarse en el diálogo y posterior acuerdo de todos los participantes, no rompe el pluralismo de los diferentes contextos empresariales dentro de una economía globalizada. Se convierte de esta forma en un horizonte al que se va acercando toda concepción de la empresa que supere una visión unitaria o dual. De hecho, la consideración del cliente derivada de la apuesta por la calidad o el respeto por las generaciones futuras derivado de la responsabilidad ecológica, están avanzado en la idea del acuerdo como base última de la credibilidad social.

Sin embargo, la efectividad de este horizonte en el día a día de la actividad empresarial puede diluirse ante la excesiva idealidad de este contrato moral. Puede conducirnos incluso a perder la visión crítica y a mantener posiciones conformistas frente a la extrema desigualdad de oportunidades que define toda actividad empresarial.

De ahí que el reto de la ética empresarial no sólo radique en constituirse en instancia crítica desde la que denunciar estas condiciones asimétricas de participación, sino que debe dar un paso más y desde sus fundamentos normativos debe ser capaz de proponer estructuras y mecanismos participativos que posibiliten este diálogo y posterior consen- 
so o, en su defecto, los compromisos y negociaciones que, pese a no cumplir las condiciones expuestas, puedan acercarse lo suficiente para que el equilibrio de intereses conseguido merezca el calificativo de justo. Esta es la tarea de la ética empresarial considerada ahora como instrumento de gestión, en la que se engloban toda una serie de instrumentos que van incorporándose a la actividad empresarial, como pueden ser los códigos éticos, los balances y auditorías éticas, los estilos de dirección participativa, los fondos éticos de inversión, etc. 